\title{
LIBERTAD Y COMUNIÓN: ALGUNOS ABORDAJES PARA PENSAR LA ARTICULACIÓN ENTRE LA MISMIDAD Y LA ALTERIDAD EN LA FILOSOFÍA DE GABRIEL MARCEL
}

\author{
Martín Grassi* \\ doi:10.11144/Javeriana.uph31-63.1cma
}

\begin{abstract}
RESUMEN
En el presente trabajo intentaremos mostrar cómo Gabriel Marcel comprende la articulación del sí mismo y del otro a partir de su reflexión en torno a la contraposición entre libertad y don, de su crítica a la filosofía de la libertad de Jean-Paul Sartre y de las implicancias metafísicas del amor. Los tres abordajes indican un camino que lleva a entender al hombre en su tensión entre la mismidad y la alteridad, en el seno de una comunión fundamental, que remite, en última instancia, a lo divino. Así, los discursos metafísicos y religiosos se encuentran cruzados constantemente, lo cual, lejos de quitarle valor a su filosofía, nos enseñan al mismo tiempo un modo y una atención que debemos dar a los símbolos y testimonios sagrados.
\end{abstract}

Palabras clave: Gabriel Marcel; libertad; don; Jean-Paul Sartre; alteridad

\footnotetext{
*Universidad Católica de Argentina y Universidad del Salvador, Buenos Aires, Argentina. RECIBIDO: 23.04.14 ACEPTADO: 30.05.14 DiSPONIBLE EN LÍNEA: 02.12.14

Para citar este artículo: Grassi, M. (2014). Libertad y comunión: Algunos abordajes para pensar la articulación entre la mismidad y la alteridad en la filosofía de Gabriel Marcel. Universitas Philosophica, 31(63), pp. 235-266, ISSN 0120-5323, ISSN en línea 23462426, doi: 10.11144/Javeriana.uph31-63.1cma
} 


\title{
FREEDOM AND COMMUNION: \\ SAMENESS AND \\ ALTERITYARTICULATION IN GABRIEL \\ MARCEL'S PHILOSOPHY. SOME APPROACHES
}

\author{
MARTín GRASSI
}

\begin{abstract}
In this paper we will try to show how Gabriel Marcel understands the junction between the self and the other as appears in his reflections on the opposition freedom-gift, on his critique of Sartre's philosophy of freedom, and on metaphysical implications of love. These three approaches point out a way that leads to understand man's tension between selfhood and alterity, in the heart of a fundamental communion which refer, ultimately, to the divine. Therefore, metaphysical and religious discourses are constantly crossing but, instead of revoking value to Marcel's philosophy, this double rapport teaches us a way of attending religious symbols and testimonies in order to get close to the meaning of human experience.
\end{abstract}

Key words: Gabriel Marcel; freedom; gift, Jean-Paul Sartre; alterity 


\section{Libertad y donación}

El GIRO MODERNO DE LA FILOSOFÍA IMPUSO COMO TAREA ineludible el pensar la libertad del hombre, asumiendo todas las implicancias de dicha idea. Las nociones de auto-determinación y auto-nomía tomaron rápidamente un lugar tanto central como estratégico para poder garantizar teóricamente una experiencia humana tan cotidiana y extraordinaria a la vez; una experiencia que define la misma existencia, retrayéndose, empero, de toda definición. La tónica de una apología de la libertad pasaba necesariamente por el acento puesto en la in-determinación de la voluntad y en su in-condicionalidad: es decir, la única manera de afirmar el carácter libre de la existencia -y así la existencia, sin más- era neutralizando a lo otro de ella misma, que pudiera llegar a dar razón o fundamento de su desarrollo; en otras palabras, anulando el concurso de la alteridad y de la exterioridad en la actuación libre. Solo puede ser libre aquel que se libere, al mismo tiempo, de todo condicionamiento y de toda determinación. Solo podrá ser libre aquel que se sustraiga en su acción a todo aquello que es extraño a su libertad. Esta caracterización de la libertad ganó un lugar indiscutible en la historia moderna, por lo cual, razonablemente, aparecieron dos posibles caminos ante esta encrucijada: o bien se afirma la libertad con una cierta trascendencia (o trascendentalidad) de la subjetividad respecto al mundo y a los otros, o bien se niega la libertad en pos de la afirmación del mundo y sus mecanismos. La cuestión por la sujeción a la cadena causal define, en última instancia, la decisión en torno a la libertad del hombre. Un punto medio es impensable.

En un ambiente marcado claramente por esta polémica entre el positivismo y el idealismo, aparece una figura clave -aunque olvidada- de la filosofía del siglo XX, representante capital de la filosofía existencial francesa, a saber: Gabriel Marcel. Formado en la Sorbona de principios de siglo, bajo la presencia de la filosofía neokantiana, cuyo representante principal era León Brunschvicg, pero inspirado también por los nuevos caminos de la metafísica señalados por Henri Bergson, Marcel lleva adelante una reflexión profunda, aunque no sistemática, de las implicancias de la existencia humana, de sus dimensiones éticas, antropológicas y metafísicas. A través del análisis de experiencias humanas concretas, cargadas de valor para quien las vive, el maestro francés se aproxima al misterio del Ser, a ese misterio que nos constituye como sujetos y que impugna cualquier intento por acercarse a lo metafísico por la ventana, manteniéndose fuera de ese ámbito de participación, como un mero espectador de aquello que, por el contrario, nos involucra necesariamente. $Y$ en estas experiencias existenciales aparece 
con fuerza insospechada, por un lado, su carácter libre, y por otro, su carácter intencional, su esencial apertura a lo otro de sí mismo. Como sostenido en una paradoja irresoluble, la filosofía se encuentra con que la supuesta encrucijada que separa para siempre el camino hacia la identidad del camino hacia la alteridad era una ilusión, un modo -en última instancia, un dispositivo lógico- de poder definir conceptos que posibiliten un entendimiento de la experiencia vital. Manteniendo una tensión insoportable, una tensión que pide a gritos una resolución, Marcel señala que la experiencia de libertad es una experiencia des-quiciada, una locura para la razón que todo lo quiere definir, que llevará al gran oxímoron de una libertad excéntrica: "el ser más autónomo es, en realidad, el más comprometido" (EA, p. 254) ${ }^{1}$, dirá Marcel con firmeza.

En un texto tardío, posterior a sus Gifford Lectures, el filósofo existencial francés abordará la tensión entre alteridad y mismidad bajo las figuras de la libertad y el don (Marcel, 2007, pp. 25-43)². Escrito en la década del 50, Marcel se adelanta a la reflexión filosófica en torno al concepto de don y de donación que será clave en la filosofía francesa desde la segunda mitad del siglo pasado, la cual -con los aportes heideggerianos- toma y retoma el sentido fenomenológico y ontológico de $l o \mathrm{dado}^{3}$. Como en toda la filosofía de Marcel, los caminos metafísicos no pueden distinguirse de los éticos, ni tampoco se desentienden de la tradición religiosa cristiana, que constantemente le aporta elementos de reflexión, por lo cual no debe sorprendernos que el título original de su ensayo fuera Libertad y Gracia (Liberté et Grâce). Justamente buscando diferenciar convenientemente el terreno de la teología del de la filosofía, y buscando tomar distancia de las controversias tradicionales que giran en torno a la palabra gracia, Marcel elige el título Don y Libertad (Don et liberté). El cambio de título es significativo

\footnotetext{
${ }^{1}$ Citaremos las obras principales de Marcel según las abreviaturas utilizadas por la comunidad académica, especificadas al final de las referencias bibliográficas

${ }^{2}$ En este texto aparecido en octubre de 1952 en Mélanges offerts à Étienne Souriau Marcel retoma -por momentos a la letra- una de las sesiones de las Gifford Lectures (publicadas bajo el título Le Mystère de l'être), "Liberté et grâce" (MEII, 109-126). Nos centramos sobre todo en el ensayo por no haber sido todavía estudiado.

${ }^{3}$ Entre los filósofos que más se han dedicado a pensar esta cuestión en la fenomenología francesa pueden nombrarse a Jacques Derrida, Paul Ricœur y Jean-Luc Marion. El tema del don sigue hoy vigente, como puede verse a partir de la publicación de la obra de Marcel Henaff (2012).
} 
de por sí, en tanto que, por un lado, reemplaza el término gracia por el de don y, por otro lado, practica un enroque en el título gracias al cual pone en primer lugar lo que antes ocupaba el último. Más allá de las razones fonéticas que lo hayan podido llevar a tomar dicha decisión, el privilegio de la palabra don en el título marcará la tónica misma de todo el ensayo. Como advertimos desde el cambio de título habrá, a su vez, una circulación semántica que se mantendrá en lo sucesivo en la fenomenología de la donación entre la gracia (lo gratuito, lo gracioso, lo inmotivado, lo inmerecido) y el don, circulación que lo habilitará a restituir por momentos un término por el otro. Así, Marcel explica la intención de su reflexión:

Mi propósito es sobre todo mostrar que las nociones de libertad y de gracia no son realmente disociables, sino que se articulan la una con la otra, y que una libertad pensada sin una referencia a la gracia corre el riesgo de perder todo valor y toda significación, si no se vuelve ella misma su contrario. De allí que sea necesario estar en guardia desde un primer momento respecto al modo en que la cuestión misma de la libertad es planteada. (Marcel, 2007, p. 25).

La pregunta por el hombre, por su libertad, debe evitar los planteos antinómicos tradicionales por los cuales o bien se afirma la naturaleza contra la subjetividad, o bien se afirma la interioridad del cogito sustrayéndolo de su mundanidad. Ante esta alternativa, Marcel propone una reflexión que, evitando este dualismo, intente volver a la unidad personal, que no es del orden de un yo trascendental, sino que se debe buscar en el registro de un ser en situación (Marcel, 2007, p. 26). Esta estrategia conceptual es central, en tanto que la situacionalidad implica una cierta flexibilización de la frontera entre el adentro y el afuera, es decir, un ser en situación es un ser que, por definición, no se basta a sí mismo, pero que a la vez no se confunde con lo que lo rodea. Las reflexiones en torno al carácter encarnado del hombre permiten explorar el sentido de esta situacionalidad, revisando el significado de las nociones de pasividad y de recepetividad (Grassi, 2009, 2011a). Pero subrayemos que, desde el comienzo del ensayo, Marcel quiere mostrar que la unidad personal, que el ser de lo personal, no puede afirmarse sino trascendiendo la oposición entre lo íntimo y lo extraño, entre lo propio y lo ajeno, entre lo mismo y lo otro.

Para pensar la existencia humana es preciso abandonar los planos de la pura teoría, en tanto que la libertad implica necesariamente una referencia al terreno de lo práctico. En este terreno, en el que intentamos reconocer 
cuándo nuestro acto es libre, es probable que se confundan el carácter libre con el carácter de no-coacción (non-contrainte). Esta confusión se expresa en la noción de una libertad auténtica, la cual se caracterizaría gracias a la consideración de la propia subjetividad como causa de mi acción, es decir, que me aprehendo a mí mismo como una causa libre. El problema, indica Marcel, es que al declarar que me aprehendo a mí mismo como causa libre, uno busca unir en esa fórmula ambigua $-\mathrm{y}$, en el fondo, contradictoriala posibilidad de tratarme como causa a la vez que me capto como sujeto que trasciende toda representación objetiva ${ }^{4}$; por el contrario, propone el maestro francés que "uno de mis actos se revelará a mí mismo tanto más objetivamente libre cuanto que mi realidad de sujeto aparezca ella misma como estando más efectivamente comprometida (engagée)" (Marcel, 2007, p. 27$)^{5}$.

Una aprehensión de la subjetividad desde sí misma pareciera, en efecto, llevarnos a una noción insular e "insularisante" de lo que llamamos la realidad de sujeto, en tanto que la subjetividad se objetiva a ella misma como centro de operaciones. Pensarse como sujeto no puede asimilarse a una aprehensión. Marcel intenta dilucidar las condiciones en que una captación de sí pueda tener lugar, y se pregunta si acaso no es en el orden del amor en que debemos buscar un camino. Es gracias al otro, al amado, que puedo tratarme a mí mismo como sujeto ${ }^{6}$. En la relación intersubjetiva, tanto uno como el otro parecen tratarse en el registro de la piedad, es decir, del reconocimiento de un carácter sagrado de la subjetividad que nos obliga a

\footnotetext{
4 “Mais cette liberté qui n'est guère ici qu'evoquée et non point définie, j'ajouterai qu'il y a tout à perdre à vouloir la penser en termes de causalité, et comme nous l'avons vue il y a un instant, peut-être n'y a-t-il pas eu dans l'histoire de la philosophie d'error plus funeste que celle qui a consisté à vouloir la penser dans son opposition au déterminisme, car elle se situe en réalité sur un tout autre plan" (MEII, p. 114).

${ }^{5}$ En este sentido, Marcel afirma que la libertad entendida como indiferencia, es decir, como mera posibilidad de elección, es el grado más bajo de la libertad: solo puede hablarse de libertad cuando hay en juego algo realmente importante, por lo cual el acto libre es esencialmente un acto significativo, que otorga sentido a la existencia (MEII, p. 117).

6 "Devrons-nous nous contenter de dire que l'autre ne devient sujet pourmoi que dans la mesure où il est enveloppé dans l'acte d'amour non possessif que je lui dédie, et que c'est par assimilation à l'autre en tant qu'aimé, non en tant que conçu, que je puis en venir à me traiter moi-même comme sujet? Ceci reviendrait à dire que je n'accède à moi-même, ou que je n'approche de moi-même comme sujet, que par la piété envers moi-même" (Marcel, 2007, p. 28).
} 
retirarnos respetuosamente, evitando cualquier invasión o violencia ${ }^{7}$. Uno se consagra al otro. En la consagración, reconozco que no puedo recibir más que a condición de una renuncia a la apropiación, aunque si una apropiación es todavía concebible es solo en tanto que esta cambia de signo: es decir, se trataría más bien de ser apropiado o de ser recibido. "Yo recibo en la medida en que yo soy recibido" (Marcel, 2007, p. 29) ${ }^{8}$. Lo sagrado, entonces, aparece como sacralizador (sacralisant) en tanto que designa una acción posible ejercida no por mí, sino sobre mí. Es preciso atender a esta paradoja de fondo, que señala un comercio entre el dar y el recibir, entre la actividad y la pasividad. Esta paradoja solo puede ser comprendida si rechazamos la identificación del recibir con el padecer (como la cera recibe el sello), y si comprendemos al recibir como una respuesta a una llamada. En este registro paradojal es que Marcel quiere moverse, y su teoría de la participación reviste tal importancia justamente en tanto que trasciende esta oposición entre actividad y pasividad; y "es en este registro, justamente, que se hace posible hacer lugar al don" (Marcel, 2007, p. 29) .

Comienza, pues, Marcel a preguntarse por el don. ¿Qué es el don? En primer lugar, el don no puede considerarse como una simple transferencia, como un determinado acto comercial, en tanto que el dar algo supone, de por sí, darse uno mismo: el don es inseparable del don de sí. Esta consideración nos lleva inmediatamente al ámbito de lo intersubjetivo, debido a que en el don me doy a mí mismo a un otro. Donar es un acto que me compromete por entero, $\mathrm{y}$ en este donar hay una parte de mí mismo que parece protestar contra este darse, ya que representa un núcleo de pretensiones que no quieren

\footnotetext{
7 "Le sacré, ce n'est pas ce qui se dérobe à nos prises, c'est ce que nous-mêmes nous plaçons hors de nos prises, c'est un domaine d'où nous nous retirons, mais non por aversion: par respect, parce qu'en empiétant sur lui nous craignons de le souiller" (Marcel, 2007, p. 28). Parece haber aquí un cierto juego entre la palabra piété y empiétant, en tanto que el apoyarse puede ser a la vez algo sagrado o sacrílego, según el sentido de dicha acción. Pero no es más que una suposición, puesto que Marcel no dice nada al respecto de este juego.

${ }^{8}$ Para ver la tensión entre el darse y el pertenecerse, ver el ensayo de Marcel titulado "Appartenance et disponibilité" (RI, pp. 62-91).

${ }^{9}$ Es interesante esta expresión, en tanto que no apunta a la definición o la demostración de la existencia del don, sino en tanto que la donación solo sería pensable desde un registro metafísico que ponga entre paréntesis el valor definitorio de las oposiciones sujeto-objeto, actividad-pasividad, apropiación-recepción.
} 
ser abandonadas ${ }^{10}$. Sin embargo, para que el don tenga lugar, es preciso un abandono radical de toda pretensión de sí, es decir, que se presente como incondicional.

La incondicionalidad está ligada a lo que podría llamarse el índice absoluto que caracteriza al don. Este índice, mirado de cerca, excluye la idea de una finalidad precisable: no se dona para que... se dona simplemente. Por ejemplo, no se dona en sentido propio para hacerse beneficiario de los lazos del reconocimiento. Donar no es seducir. (Marcel, 2007, p. 30)

Esta incondicionalidad, que lleva a una de-finalización radical del don, conduce, a la vez, a una dificultad profunda que destruiría al don de su significado. Mas, en rigor, solo trascendiendo las categorías de la finalidad (y aquí Marcel nombra a Bergson como uno de los que más han apuntado a esta tarea) es que el don encuentra su verdadera esencia, en tanto que donar es derramar (répandre), es derramarse (se répandre). "El alma del don es la generosidad" (Marcel, 2007, p. 31). Lejos de una interpretación materialista, la generosidad, el derramar, el prodigar, no se asimila a un perder cierta posesión, a un estrechamiento de una cierta sobreabundancia. Más bien debemos atender a las imágenes de la luz o de la llama, pues la generosidad es como una luz que se alegra de ser luz, es decir, que, como la luz, no tiene en cuenta el límite entre el para sí y para el otro, sino que ilumina lo otro en tanto es luz ella misma; o, como la llama, que se nutre a sí misma. Esta alegría de la luz, de la generosidad, no puede pensarse más que como una cierta conciencia de un todos juntos (tous ensemble), tal como sucede en la danza, en el coro o en la orquesta, en la que el individuo es consciente de un ejercicio sinérgico, de una participación en algo que lo supera y que lo significa íntimamente. Por el contrario, "una generosidad que se complazca en ella misma deja de ser generosidad y sin duda se afecta inevitablemente de esterilidad" (Marcel, 2007, p. 32). Una filosofía que excluya la posibilidad de esta luminosidad, de esta generosidad que no se cierra sobre sí, no hace justicia, afirma el pensador existencial, a los verdaderos hechos fundamentales de la experiencia humana, tal como lo pueden mostrar los casos del artista, del héroe o del santo.

\footnotetext{
${ }^{10}$ Para ver esta ambivalencia de un yo, que aunque pueda entregarse al otro, también puede anularlo en pos de su afirmación, ver el ensayo de Marcel: "Moi et autrui" ( $H V$, pp. 15-35).
} 
Por ello, es preciso apuntar a una metafisica de la luz (métaphysique de la lumière) que se construiría desde los análisis de la generosidad y de la comparación entre generosidad y luminosidad. Atendiendo a la generosidad, Marcel muestra que entre esta y el don la relación es doble: por un lado, la generosidad es aquello gracias a lo cual el don es posible, es el alma del don; por otro lado, la generosidad misma aparece como un don, y quizá como el don supremo, lo cual significa, negativamente, que no puede ser obtenida ni por uno mismo ni por otro. No podemos hablar de "obtener", en tanto que algo se obtiene a fuerza de insistencia y de tenacidad, y lo que se obtiene es siempre un resultado. "El don precisamente no es asimilable a un resultado; no resulta: surge (il jaillit); es resplandor (éclat) o surgimiento (jaillissement)" (Marcel, 2007, p. 33). Ante la generosidad, por ello, se suscitan dos reacciones opuestas: la admiración y, correlativamente, el resentimiento. Por otro lado, tal como la generosidad no es discernible más que gracias al don que prodiga, de la misma manera la luz no se deja reconocer más que gracias a lo que ella ilumina (éclaire). Es debido a la luz que toda distinción es posible, aún respecto de lo que no es ella, es decir, la oscuridad. Como en el caso del don, "la luz es su propio principio" (Marcel, 2007, p. 33), lo cual permite comprender por qué trasciende toda definición, en cuanto que ella es la que hace posible el acto mismo de definir.

Volviendo ahora al análisis del don, Marcel se detiene en el punto de vista del beneficiario. Para que el don sea efectivo es necesario que este reconozca el don en tanto que don. Para ello es preciso que el beneficiario esté seguro que una cosa le ha sido dada y no simplemente prestada, para lo cual necesita una seguridad formal que provenga del donatario. Así, parecería que la palabra, sea escrita o no, constituye el don en tanto que tal. En efecto, esto se verifica en los casos en los que se trata de una cosa particular, designable, y de la cual puede identificarse a su poseedor. Pero sucede también que la palabra don se emplea fácilmente para designar una disposición innata, diferente a aquellas que son obtenidas a fuerza de paciencia y de tenacidad, como cuando hablamos de "don musical". Esta metáfora debe tenerse en cuenta seriamente porque nos permite considerar la vida como el don fundamental, o mejor, el hecho de ser en el mundo con todas sus implicaciones concretas. Este ser en el mundo implica estar inserto en condiciones determinadas, comprometido en un determinado lugar de la aventura humana, lo cual lleva a Marcel a hablar de una no-contingencia del dato empírico (non-contingence du donné empirique) (Marcel, 2007, p. 
34) ${ }^{11}$. Hay filosofías que se contraponen a este carácter fundamental del don a partir de una exigencia de crítica, tal como el marxismo ateo o el nihilismo sartreano, por lo cual Marcel habla de un "yo reflexivo" (moi réfléchissant) que denuncia y critica al "yo orante" (moi orant), al yo que da gracias (le moi qui rend grâce) (MEII, pp. 85-108). No se trata, de ninguna manera en Marcel, de desestimar la centralidad de la reflexión, la cual es inseparable de la vida humana (Grassi, 2011b), sino de denunciar una actitud crítica que se torne ciega ante aquello que se me da. En rigor, es la reflexión segunda la que hace frente a una reflexión primaria, y cuyo fundamento se encuentra en la conciencia de que el yo de la reflexión no puede agotar la totalidad del yo, y que denuncia la postulación de que la actitud del "yo orante" es de índole puramente subjetiva. La reflexión segunda, entonces, es aquella que reconoce en la subjetividad a un ser que participa de una realidad plenaria que lo constituye. Solo en esta perspectiva podemos entender a la vida como un don fundamental, como algo que me es dado, que sin ser obtenido me constituye radicalmente. De algún modo, dice Marcel, la vida me ha sido dada para que le confiera sentido. Esta afirmación nos ubicaría en la tensión entre la libertad y lo que algunos llaman Gracia, articulación que no es del orden de la causalidad y de la identidad. "Estamos en lo no-identificable". No puede hablarse de la Gracia como un efecto de una causa divina, puesto que Dios no puede ser ni identificado ni tenido por causa. Se trataría, entonces, de una realidad que no puede ser vivida más que desde las coordenadas de un recurso a un Tú Absoluto (Grassi, 2013) ${ }^{12}$. Negar la realidad de la gracia por la imposibilidad de remitirla a su causa es contradictoria en tanto que la realidad negada no es, justamente, del orden objetivo-causal. Más allá de las palabras de Marcel, pareciera que el don fundamental no remite, pues, a ningún donatario, en el sentido de un alguien que puede ser identificado como el poseedor de la vida que luego me da.

\footnotetext{
${ }^{11}$ Aquí Marcel refiere esta expresión a obras tempranas que no especifica en el texto. Esta expresión aparece ante todo en el marco de la encarnación y la situacionalidad del existente en el mundo, y en la necesidad de pensar la participación contra los dualismos del idealismo entre la apariencia y la realidad. $\mathrm{Al}$ respecto, véase: $F P, \mathrm{p} .113$. Se vuelve a referir a este texto en $R I$, pp. 37-38.

12 "C'est donc uniquement pour autant que d'une façon quelconque je reconnais, je salue cette révélation, que je puis être amené à appréhender la vie et ma propre vie comme don. Mais il est non moins vrai que cette appréhension peut avoir lieu sans que j'aie une conscience articulée et distincte de la Révélation en tant que telle" (MEII, p. 123).
} 
De alguna manera, afirma el filósofo francés, la libertad no puede afirmarse ni realizarse más que en presencia de un Tú Absoluto y como en tensión con Él, aunque la relación entre libertad y gracia sea más sutil y secreta. Para comprender esta articulación es preciso, primero, alejarse de la concepción, propia del orden político, de la libertad como una cierta posesión. Si bien esta forma de entender la libertad supone una defensa del privilegio inalienable del hombre que vive verdaderamente como hombre, tal como han postulado los filósofos antiguos (los estoicos, sobre todo) y Spinoza. El problema es saber si una actitud tal como la de los estoicos es conforme a nuestras condiciones concretas de inserción en el mundo (Marcel, 2007, p. 37). En este punto el análisis del don muestra su utilidad. Ser libre implica, necesariamente, la posibilidad de reevaluar el compromiso en el que me encuentro y de decidir aquello que quiero ser, situado en las condiciones en las que actúo y que contribuyen, a su vez, al proceso de autocreación, "al término del cual estoy llamado a constituirme en el ser" (Marcel, 2007, p. 39). En este sentido, la fidelidad se aleja de una mera constancia, de una armadura meramente formal, pegada a la letra de mi promesa, para tornarse creativa, lo cual significa derogar de hecho tal o cual compromiso tomado en su literalidad ${ }^{13}$. Es evidente que la libertad está signada esencialmente por la posibilidad de obrar y de deshacer sus obras (désoeuvrement), es decir, en tanto que está llamada a decidir sobre sí. Pero esta libertad, se pregunta Marcel, "¿en qué sentido y a título de qué puede ser afirmada?" (Marcel, 2007, p. 39). No se trata de un saberse libre, según el cual todo saber implica un objeto y la despersonalización del sujeto que sabe, sino del hecho de que una tal despersonalización es impensable: nadie puede tomar mi lugar para saber si soy o no libre. Se trataría, más bien, de una creencia (croyance), siempre y cuando se reconozca a la creencia en su especificidad, es decir, lejos de asimilarla a un conocimiento imperfecto: "creer es en realidad un modo de ser más que de conocer" (Marcel, 2007, p. 39) ${ }^{14}$. Estas reflexiones, advierte Marcel, no están desconectadas de aquellas que giraban en torno al don. Así como no debe confundirse el recibir (recevoir) con el padecer

\footnotetext{
${ }^{13}$ Si bien no desarrolla aquí Marcel la noción de fidelidad creadora, se trata de uno de sus aportes fundamentales de su filosofía, y de una de las experiencias nodales para acceder al misterio ontológico. Véase: "La fidélité créatrice" (RI, pp. 220-259).

${ }^{14}$ La cuestión de la creencia y de la fe tiene un lugar especial en la filosofía de Marcel, en tanto que el sujeto de la fe es distinto del sujeto del saber. Es gracias a la fe que el hombre llega a ser persona, a individualizarse en el acto de comunión con Dios y con el mundo (Grassi, 2013).
} 
(subir), tampoco debe confundirse el crear (créer) con el producir (produir). $\mathrm{Y}$ esta denuncia implica una resignificación de la subjetividad y de su carácter libre.

Una creación cualquiera no es posible más que sobre la base de una receptividad que es ya por esencia activa, y que de algún modo preforma esta creación misma. De ser así, la libertad, entendida como creación de sí por sí, no será concebible más que por un ser que, si va al fondo de sí mismo, está llamado a aparecerse como siendo en el fondo don, lejos de poder atribuirse en cualquier sentido que sea esta caricatura de autarquía (aséité) que evocan la mayor parte de los ateísmos contemporáneos. (Marcel, 2007, p. 40)

Es en el corazón de la situación concreta que me aparezco a mí mismo como donado, como dado a mí mismo. La pregunta por quien me dona, como ya señaló Marcel, no tiene verdaderamente sentido. Si dijéramos que es Dios quien nos da, debemos descartar sistemáticamente toda interpretación causalista. Deberíamos decir, mejor, que la situación funciona como llamado, como llamado del yo absoluto (moi absolu) que aspiro a ser al yo que soy y que se esfuerza por superar sus propios límites. A pesar de la terminología fichteana, cuyos supuestos Marcel quiere evitar, aparece aquí la distancia entre el yo que soy y el yo que aspiro ser ${ }^{15}$. Es aquí donde una metafísica del don y de la generosidad puede introducir cierto aire o ventilación. Este término ventilación (ventilation) le parece a Marcel absolutamente indispensable para reintegrar la libertad en un contexto en el que se espiritualice (Marcel, 2007, p. 41). La metafísica del don impugna el intento de autarquía de una libertad estoica, y la inserta en el mundo de la intersubjetividad. Esta inserción en la intersubjetividad llevaría a una meditación en torno a las relaciones entre la libertad y el amor, que en este texto apenas se anuncia, pero que luego retomaremos hacia el final del artículo. "Sería preciso investigar si una actividad que torna contra el amor no sería en fin de cuentas una libertad que se invalida a ella misma" (Marcel, 2007, p. 42). Entramos aquí al ámbito misterioso de una libertad que, por definición, puede traicionarse a sí misma, y que señala el centro mismo del drama de la aventura humana.

Si la libertad está articulada a la Gracia (Grâce), le es igualmente esencial el poder romper con esta juntura (jointure) exquisitamente delicada, y,

\footnotetext{
${ }^{15}$ Esta distancia "interior" la ha trabajado también Marcel desde la contraposición entre $m i$ ser y mi vida, contraposición que posibilita el recogimiento. Véase: "Ma vie" y "Le sens de 'ma vie': Identité et profondeur"' (MEI, pp. 163-185/187-211).
} 
desplegándose en aquello que le aparece como su dirección propia, hacer en realidad el juego a fuerzas adversas. El rol y el lugar exacto de estas fuerzas en la economía universal no pueden ser para nosotros más que objetos de conjetura; y nuestra condición parece ser tal que en el horizonte de nuestro esfuerzo y de nuestra prueba, constituyen los nubarrones (nuées) en los que la amenaza queda suspendida sobre nosotros sin que nos sea posible afirmar si esta amenaza debe ser en última instancia juzgada como inexorable. (Marcel, 2007, pp. 42-43)

La Gracia aparecería, entonces, como el contrapunto a aquellas fuerzas que nos cierran sobre nosotros mismos, y que nos sumergen en la ilusión de que en el abandono del horizonte de la donación y de la generosidad nuestra libertad se realiza. Estas fuerzas dia-bólicas -en su sentido etimológico de separación-, si bien son conjeturadas, y encuentran un sentido propio en el ámbito religioso, pueden ser consideradas como necesarias en nuestra condición existencial, en tanto que nuestra libertad se encuentra esencialmente en esta encrucijada permanente entre el consentimiento al Ser y al rechazo a su Invocación. ${ }^{16}$ En otras palabras, es esencial a la libertad el estar tendida entre la alegría humilde de participación y de comunión, y la exigencia de una independencia y autonomía que, si bien expresan una pretensión noble, llevan a falsear la dinámica misma de la vida personal.

\section{Comunión y alienación: la crítica de la filosofía de Jean-Paul Sartre}

EN ESTA BÚSQUEDA DE UNA ARTICULACIÓN ENTRE libertad y alteridad, el filósofo con quien más se ha enfrentado Gabriel Marcel ha sido, sin duda, Jean-Paul Sartre. Mientras que en sus primeros escritos Marcel se contrapuso ante todo a la corriente idealista, sobre todo en la persona de León Brunschvicg, en los escritos posteriores a la Segunda Gran Guerra dedicó muchas páginas a criticar con dureza la filosofía sartreana. Debemos recordar que Sartre había tomado en esos años, junto a un grupo importante de filósofos y literatos,

\footnotetext{
${ }^{16}$ La última expresión es el título original de la obra que luego se publicará bajo el nombre de Essais de Philosophie concrète. La primera es un título de Aimé Forest, quien ha escrito dos obras - publicadas en la colección Philosophie de l'esprit, dirigida por Lavelle y Le Senne, y en la que Marcel ha publicado varias de sus obras- tituladas Du consentement à l'être y Consentement et création, que están en clara sintonía con la filosofía marceliana. Marcel afirma en otra obra: "Il est peut-être de mon essence de pouvoir n'être pas ce que je suis; tout simplement de pouvoir me trahir" (EA, p. 154).
} 
una popularidad y una relevancia cultural muy grande como uno de los representantes más significativos del existencialismo, y toda su filosofía se constituía desde un modo muy peculiar de entender la existencia y la libertad. Marcel, por otra parte, había quedado preso del mote de existencialista cristiano gracias a Sartre quien, en su ensayo "El existencialismo es un humanismo", distinguió entre un existencialismo teísta y un existencialismo ateo. Al quedar enlistado en una misma corriente filosófica, Marcel sintió que su pensamiento era traicionado e incomprendido, por lo cual queriendo deshacerse de esa etiqueta filosófica, admitió tan solo que se llame a su filosofía neosocratismo o socratismo cristiano (MEI, p. 5). Como intentaremos mostrar en este apartado, el existencialismo en ese momento popular era una filosofía radicalmente opuesta a la de Marcel, pues para autores más presentes en la cultura de comienzos de la segunda mitad de siglo, el existencialismo tomaba la forma de una filosofía de lo absurdo, de la gratuidad, de la libertad absoluta y era, por otra parte, muy cercana al marxismo soviético.

La relación personal entre Marcel y Sartre no fue profunda ni sostenida en el tiempo. Sartre participó como joven filósofo en las tertulias que Marcel organizaba en su domicilio los días viernes. Y parece que su meditación en torno a la náusea -tema principal de su primera genial novela-fue motivada por el mismo Marcel ${ }^{17}$. Sin embargo, después no tuvieron más que algunos encuentros fortuitos, por lo que dejaron de verse y tratarse definitivamente (Marcel, 1984, p. 552). En el plano intelectual, mientras que en Marcel encontramos numerosas referencias a la filosofía de Sartre, dirigiéndole críticas muy interesantes, Sartre se refirió a él en muy pocas ocasiones, desestimando sus observaciones. Es probable que, por un lado, la militancia filosófica de Sartre se encontrara más comprometida con una filosofía de la historia de corte marxista que con consideraciones metafísicas como las que llevaba adelante Marcel y, por otro lado, que la enorme intolerancia y superficialidad de gran parte del sector católico lo hubiera llevado a desoír sin más las voces que provenían de dicho frente ${ }^{18}$.

\footnotetext{
${ }^{17}$ Marcel cuenta que fue él quien le recomendó a Sartre, en una oportunidad en la que éste se encontraba en su casa, que debería hacer un análisis de lo viscoso (visqueux), análisis que luego se encontraría profundizado en su novela La nausée (Marcel, 1946, p. 121).

${ }^{18}$ Como católico y filósofo que soy, me da una enorme vergüenza encontrar libros católicos como el de Pierre Boutang, titulado Sartre est-il un possédé ? (1946). La imposibilidad
} 
En lo que respecta a la filosofía de Sartre, parece que ha sido influida positivamente por las reflexiones de Marcel, sobre todo en lo que respecta a las nociones de existencia, encarnación, intersubjetividad, situación y libertad (Cañas, 2005). Sin embargo, las diferencias entre ambos pensadores se profundizarán desde esas mismas nociones que parecen encontrarse en el corazón de toda filosofía de la existencia. Al respecto, Marcel escribió un artículo dedicado a Sartre, "L'existence et la liberté humaine chez J.-P. Sartre" (1946, pp. 111-170), en el cual se encuentran sus críticas más agudas. La crítica central, en efecto, se dirige a que la filosofía sartreana es una filosofía de la self-consciousness, es decir, del ego, que indefectiblemente pierde la posibilidad de un encuentro auténtico entre un yo y un tú, por lo cual todo otro se encuentra en el registro del $e l l{ }^{19}{ }^{19}$, razón por la cual Marcel considera a Sartre como un exponente más de la filosofía idealista, que al postular la posición absoluta de sí descuida el sentido de la receptividad entendida como disponibilidad (y no como mera pasividad) ${ }^{20}$.

de un verdadero diálogo filosófico se cortaba de cuajo desde este tipo de acusaciones o ataques moralistas. Lamentablemente, Marcel cayó muchas veces en este tipo de diatribas, tan contrarias a su modo de filosofar, pero que seguramente eran motivadas por el espíritu católico de la época a la que pertenecía. Por otra parte, en su afán por liberarse del mote de existencialista y en su voluntad por pertenecer y ser reconocido como parte de la Iglesia Católica -dificultada también por la rigidez de la neo-escolástica-, seguramente se hizo portavoz de las calumnias y del rechazo absoluto que despertaba el existencialismo ateo.

${ }^{19}$ Respecto a una filosofía de la auto-conciencia, Marcel escribe: " $L a$ selfconsciousness et le lui; philosophie de la selfconsciousness. Ici les autres sont vraiment extérieurs à un certain cercle que je forme avec moi-même. De ce point de vue il est impossible pour moi de communiquer avec eux; l'idée même d'une communication est impossible. Je ne pourrai $m$ 'empêcher de regarder cette réalité intrasubjective des autres comme l'émergence d'un $X$ absolument mystérieux et à jamais insaisissable" (EA, p. 152).

20 "Au fond, pour Sartre, un être libre -ceci me paraît extraordinairement important: c'est là que nous voyons à nu cette disposition qui est vraiment l'orgueil métaphysique - pour Sartre, un être libre repugne à recevoir: on dira même qu'il est tenu de niers vis-à-vis de lui-même qu'il ait reçu. Mais je me demande si l'auteur de La Nausée ne se rend pas ici coupable de l'erreur plus grave qui puis se être imputée à l'idéalisme dans son ensemble. Bien entendu, il faudrait, comme toujours dans l'histoire de la philosophie, introduire bien des nuances. Mais si nous prenons l'idéalisme chez Kant et chez certains de ses successeurs, par le fait qu'ils concevaient l'esprit comme une activité constructrice, ils étaient portés à confondre radicalement le fait de recevoir et celui de subir: il semble que poureux la réceptivité soit, au fond, une caractéristique de la matière. Ici, nous voyons une fois de plus le rôle néfaste des images matérielles. Il a été question tout à l'heure, quelque part, de récipient. Je crois qu'à partir du moment où on interprète le sujet recevant comme «récipient», tout est perdu. Je pense d'ailleurs que sur ce point il est absolument 
En este punto, resulta interesante señalar el modo en que puede entenderse la receptividad desde las coordenadas de la experiencia de la hospitalidad. En primer lugar, es necesario descartar - para Marcel- el sentido meramente pasivo e inerte de la palabra recibir que se expresa cuando decimos, por ejemplo, que la cera recibe un molde. En este caso -como en muchos otros"recibir es simplemente padecer" ( $R I, \mathrm{p}$. 46). Pero fijemos la atención sobre la relación que presenta el hecho de que un hombre reciba a otro en calidad de huésped. En este caso es claro que el recibir no es un mero sufrir. Por el contrario, la riqueza de la preposición chez (en casa de) señala una plenitud ontológica de la hospitalidad en el acto de recibir en mi casa a quien me visita, riqueza que no ha sido tomada suficientemente ${ }^{21}$ en consideración por los filósofos. En efecto, no hay chez más que respecto a un yo (soi), es decir, respecto a alguien que pueda exclamar yo. Mas cuando digo, por caso, chez moi (en mi casa) se admite que yo mismo impregno a mi ambiente vital, a mi hogar, de una cualidad propia que permite decir que es, justamente, mío. Gracias a esta cualidad me reconozco en él y mantengo con él relaciones de familiaridad. Es interesante ver en hechos tan cotidianos como mudarse, alojarse en un hotel, o comer afuera, etc., esta negación de la familiaridad que uno establece, en cambio, con su hogar. En otras palabras, $m i$ hogar no me es, por definición, extraño (RI, pp. 46-47). Aún más, cuando recibo a alguien en mi casa, a un extraño respecto a mi hogar, lo admito y lo hago participar de esta zona cualificada que sería mi casa (RI, p. 47). Es decir, cuando recibo en mi casa a alguien, todo el ambiente lo recibe también, ya que el ambiente habla de mí y acompaña mi hospitalidad. Yendo más allá de Marcel con los análisis, podríamos pensar que cuando uno le dice al huésped que "se sienta como en su casa" es un cierto modo de prolongar la familiaridad que él ya tiene conmigo al ambiente que, justamente, lleva mi presencia como su sello. Sería muy difícil imaginar que alguien pueda sentirse a gusto en un ambiente si antes no hay una relación de simpatía entre él y quien lo

indispensable de renouer une certaine tradition aristotélicienne, car chez Aristote cette erreuer a été évitée, on ne peut le contester. Mais à partir du moment où on méconnaît ce caractère propre de la réceptivité, non seulement peut-être chez l'être spirituel, mais diraije chez l'être vivant, à partir du moment où on cesse de voir que recevoir ce n'est pas du tout subir, ce n'est pas du tout subir une empreinte à la façon de la cire, il devient impossible de concevoir l'insertion concrète ou organique de l'être individuel dans le monde. Dès lors on n'a plus que deux termes en présence: une facticité en quelque sorte inerte, et une liberté qui la nie pour l'assumer en suite d'une façon très mystérieuse" (Marcel, 1946, p. 161).

${ }^{21}$ Véase la nota 22. 
recibe. Sentirse incómodo en una casa es muchas veces la exteriorización de no sentirse cómodo frente a quien lo hospeda. En el acto de hospitalidad, entonces, se espera que el huésped forme parte, participe, de esta plenitud que es mi hogar, en tanto mío. De aquí que, en este caso, recibir no signifique de ningún modo sufrir, llenar un vacío con una presencia extraña, sino que es acoger a otro y hacerlo partícipe de la plenitud de mi vida que impregna el ambiente mismo donde vivo. En este sentido, recibir es un acto de donación porque yo le ofrezco algo propio a alguien extraño para que él también lo haga propio; y como esto propio se identifica conmigo -y por tal razón me es familiar-, soy yo mismo el que se ofrece a quien hospedo ${ }^{22}$.

En una filosofía que establezca la primacía de una subjetividad que no reconoce una alteridad, el mundo termina revelándose como absurdo, porque no hay modo de trascender la subjetividad hacia algo que la contenga y que la ilumine; de allí que Marcel afirme que la filosofía de Sartre es idolocéntrica ${ }^{23}$. Para Sartre, cualquier experiencia de comunión o de comunidad es sospechosa (como, por ejemplo, la familia), lo cual se debe, para Marcel,

\footnotetext{
22 "Si nous fixons ici nos yeux sur l'acte d'hospitalité, nous verrons immédiatement que recevoir n'est point du tout combler un vide avec une présence étrangère, mais faire participer l'autre à une certaine plénitude. Le terme ambigu de réceptivité s'applique donc à un clavier fort étendu qui s'étend du pâtir, du subir - aun don de soi; car l'hospitalité est un don de ce qui est sien, c'est-à-dire de soi-même" (RI, p. 48). Para el análisis del recibir, véase: RI, pp. 137-140. Si bien estas reflexiones están en el marco de pensar la sensibilidad, el conocimiento sensible, son sumamente luminosas para entender las relaciones interpersonales. El tema de la hospitalidad también ha sido retomado por Jacques Derrida y Paul Ricœur.

23 "Telle est, dirai-je, la révélation, l'illumination négative [propia de la náusea, que revela la absurdidad]. J'attire votre attention sur ces deux mots, qui commandent tout la pensée de Sartre: et c'est parce que cette illumination est négative que sa philosophie sera en dernier ressort une philosophie du néant. Il serait à vrai dire essentiel de se demander si une illumination négative est réellement possible, et sur ce point je ferais quant à moi les plus expresses réserves. Qui dit illumination dit lumière en effet, mais l'absurdité, c'est l'opacité même, c'est le contraire d'un foyer. S'il y a ici une lumière, elle ne peut venir que du moi lui-même, en tant qu'il se dresse devant elle et contre elle. Mais ce moi-là est au sens étymologique du mot eidôlon, idole. Et nous apercevons déjà ici cette vérité à mon sens capitale que la pensée de Sartre est eidôlo-centrique. Pensée, non point sagesse. Du point de vue de Sartre, ce que les hommes appellent expériences ou sagesse est probablement avant tout une façon active de se mentir à soi-même, de se dissimuler cette fondamentale absurdité qu'est l'existence même. Il n'est pour s'en rendre compte que de se référer à ce que les hommes désignent communément sous le nom d'expérience" (Marcel, 1946, p. 125).
} 
a su modo de ir hacia el mundo, de referirse a él; "el mundo de Sartre -dice Marcel- es el mundo visto desde un café” (1946, p. 129). En otras palabras, es un mundo visto por un espectador desinteresado, que no participa del mundo sino que se enfrenta a él desde fuera. Así, la subjetividad parece entenderla Sartre desde el postulado de la soledad, razón por la cual el otro se me revela como un intruso, como una amenaza, tal como parecen mostrar sus análisis de la mirada y de la vergüenza ${ }^{24}$. Marcel entiende que en Sartre la comunión entre un yo y un tú es desplazada, sin posibilidad de un verdadero encuentro; recordemos que, para Sartre, el ser-para-otro es una dimensión del para-sí, y toma la forma de un conflicto y una polémica entre la libertad de sí, que se afirma queriendo negar la otra, y la libertad del otro, que quiere afirmarse a costa de la propia ${ }^{25}$. No hay lugar en Sartre-afirma Marcel-para un nosotros-sujeto (nous-sujet) auténtico, aquel del amor y de la amistad, sino tan solo de un nosotros-sujeto práctico, es decir, de una pertenencia a un nosotros que se da simplemente en la esfera práctica, en tanto que actúo junto a otros ${ }^{26}$. En una filosofía de la primacía de un sujeto que se enfrenta al mundo y a los demás para apropiárselos, no puede haber lugar para la

\footnotetext{
${ }^{24}$ Sartre pone como ejemplo el que alguien se encuentre escuchando detrás de la puerta una conversación ajena, protegido de cualquier otra mirada que lo descubra (Sartre, 1998, Par, III, Cap. 1, IV). Ante ello Marcel sostiene que: "Je pose en principe que je ne risque pas d'être surpris; ma solitude est ici ma donnée, mon postulat. Il resterait à se demander si c'est là la situation humaine par excellence. Ce qu'on voit distinctement, c'est que, pour Sartre, la reconnaissance d'autrui comme tel n'est pas séparable du choc de ce qu'il appelle une liberté, et d'un liberté adverse qui la menace" (Marcel, 1946, p. 147).

${ }^{25}$ Sartre desarrolla su reflexión en torno al ser-para-otro en la tercera parte de El Ser y la Nada. Hacia el final de la exposición, afirma claramente que "la esencia de las relaciones entre conciencias no es el Mitsein, sino el conflicto" (Sartre, 1998, p. 531).

26 "Comment, en effet, va se spécifier la théorie de la connaisance d'autrui? Elle est tout entière orienté evers cette afirmation massive que la communication et en fin de compte vouée à l'échec, que si je me saisis comme engagé dans un nous-sujet, c'est par exemple dans la marche cadencée des soldats, ou encore dans le travail rythmé d'une équipe, ce rythme étant produit par moi, et se fondant en fondant en même temps avec le rythme de travail ou de marche de la communauté concrète dont je fais partie. Mais, en ce qui concerne le nous-sujet authentique, celui de l'amour ou de l'amitié, il faut avouer que la pensée de Sartre se révèle radicalement agnostique, voir nihiliste" (Marcel, 1946, p. 149). El tratamiento del nosotros por Sartre se encuentra en la tercera parte, capítulo III, punto III de El Ser y la Nada. En las antípodas de Marcel, Sartre (1998, p. 529) afirma: "la experiencia del nosotros-sujeto no tiene ningún valor de revelación metafísica”.
} 
comunión, región en la que la apropiación es impracticable ${ }^{27}$. Y esta primacía del sujeto se comprende, en rigor, desde la comprensión de la libertad que tiene Sartre: la libertad se comprende como un absoluto ${ }^{28} \mathrm{y}$, por tanto, como una posición de sí que ignora cualquier tipo de donación que le viniera de fuera y a la cual respondería. Esto es, en palabras de Marcel, una libertad que se afirma contra la gracia o el don que le es dado, una libertad que se basta a sí misma ${ }^{29}$. Esta filosofía existencialista queda por debajo incluso del idealismo frente al cual reacciona, puesto que, según Marcel, lo absoluto

27 "Il est manifest que tout cette dialectique, dont on ne contestera pas la force et l'agilité, repose entièrement sur la négation du nous-sujet, c'est-à-dire de la communion. Pour Sartre, ce mot est vide de sens et ceci à tous les stades et vous pensez bien que je ne parle pas seulement de la communion religieuse ou mystique. Pourquoi? Parce que dans cet univers la participation elle-même est impossible. C'est là le point essentiel, philosophiquement parlant. Il ne peut donc plus être question que d'appropriation, et cela dans un domaine où l'appropriation est justement impracticable" (Marcel, 1946, pp. 151-152). Al respecto Glenn (1984, pp. 544-545) selaña: "I have suggested that the basic divergence in orientation between these two philosophers is best expressed by saying that Marcel's philosophy is a philosophy of communion and Sartre's a philosophy of alienation. Yet in a way this characterization of their relation is somewhat misleading. It seems to imply that the relation is one of simple opposition -and it is apparently such suggestions that have led Marcel to be slightly distrustful of comparisons of his thought with Sartre's. The truth is somewhat more complex, for Marcel's philosophy is in a fundamental way more comprehensive than Sartre's. Sartre construes alienation as the essential human condition -however much he may deny that human beings have an essence-and thus excludes the very possibility of real communion. But Marcel's orientation toward communion has not similarly prevented him from recognizing the metaphysical possibility-and the pervasive factual reality - of alienation. Although consistently holding to the conviction that human beings are most truly themselves in communion, Marcel has not forgotten that 'it may be of my essence to be able not to be what I am; in plain words, to be able to betray myself' and that to which I am essentially united. He has recognized the temptations that may lead one to despair -to reject being, betray community, become alienated from one's own incarnate existence, and employ one's freedom for its own degradation. Both Marcel's philosophical and his dramatic writings bear witness to such possibilities".

28 'Sartre n'a pas hésité à déclarer oralement qu'il est le seul à pouvoir parler aujourd'hui d'absolu, car la liberté à ses yeux est bien un absolu; je crois que c'est vraiment la plus extraordinaire aberration que nous trouvons chez lui" (Marcel, 1946, p. 152).

29 “... [C] ]ette philosophie refuse la grâce sous toutes ses formes. Personne ne semble avoir jamais été moins capable que Sartre de comprendre ce que ce peut être pour une conscience que de recevoir, et corrélativement, d'ailleurs, ce que c'est que le don. Je n'enveux d'autre preuve que l'analyse si étrangement déformante à laquelle il soumet la générosité" (Marcel, 1946, p. 159). 
de la libertad se expresa en su anhelo y afán por constituirse como un ser completo y consistente, es decir que el hombre intenta constituirse como un ser-en-sí y para-sí, por lo cual esta divinización a la que tiende termina en una empresa vana y absurda, razón por la que la vida del hombre es una pasión inútil ${ }^{30}$.

\section{La experiencia nodal del amor: la significación metafísica del nosotros}

A DIFERENCIA DE UNA FILOSOFÍA DE LA MISMIDAD o de la autoconciencia, la principal consigna de Marcel es pensar la intersubjetividad, no en tanto articulación de seres aislados que se aúnan en la práctica por un interés común, sino desde la primacía ontológica de una comunidad, de un nosotros que no se limite a un determinado grupo por oposición a otro, de una nostridad, de una comunión universal que alcanza también a los seres del mundo y a Dios (la noción clave es la de participación). Ya desde sus escritos tempranos, Marcel se preocupa por entender esta comunión, por lo cual no duda en colocar al amor en un lugar clave para iluminar esta dependencia radical del sujeto respecto a un nosotros. Por ello, intentaremos mostrar la importancia central del amor en una metafisica del nosotros, que es también una metafísica de la luz y de la donación, como la de Gabriel Marcel ${ }^{31}$.

\footnotetext{
30 "Cet existentialisme -vous me rendrez cette justice que je n'ai pas abusé de ce mot-qui, historiquement, se développe au départ en réaction contre le système de Hegel, nous le voyons maintenant déboucher, comme les tunnels hélicoïdaux de la ligne du Saint-Gothard, bien au-dessous du niveau initial. Il est trop clair, en effet, que du point de vue même de Hegel, la conception de l'être en soi se situé à un plan tout à fait inférieur de la dialectique. L'affirmation constante de Sartre, c'est d'ailleurs que l'homme est une passion inutile, ou encorequ'il aspire vainement à réaliser l'impossible synthèse que constituerait un être en soi, poursoi. L'enterprise humaine est une enterprise, inévitablement manquée, de divinisation de soi" (Marcel, 1946, p. 162).

${ }^{31}$ La filosofía que propone Marcel se halla, como admite él mismo, ante la alternativa perturbadora de intentar resolver las dificultades que presenta la participación en todas sus formas, cayendo así o bien en una dogmática desconocedora de sus principios vitales y de una teología sacrílega, o bien dejando simplemente subsistir tales dificultades etiquetándolas de misterios. "Entre ces deux écueils je croisqu'il existe une via media, un chemin étroit, difficile, périlleux; c'est celui que je me suis efforcé non de tracer, mais de repérer. (...) Mais-Platon, je pense, l'a vu avec une incomparable netteté-, ce chemin ne peut être décelé que par l'amour, il est visible pour lui seul: et ici apparaît un caractère plus profond peut-être que tous les autres de ce méta-problématique dont j'ai tenté d'explorer certaines régions" (PA, p. 88). Julia Urabayen Pérez (2004, p. 136) explica: "Esta vía media
} 
La solución monadista es inaceptable para comprender la intersubjetividad. En unas notas tempranas del Journal Métaphysique, Marcel se pregunta en torno a la individualidad y a la comunicación entre las individualidades; allí indica que la afirmación de un cogito que tiene un contenido empírico mundano, no puede, sin embargo, abrirse a la pluralidad, pues dichos otros siguen suspendidos al acto de pensarlos. En otras palabras, si el cogito se identifica con un para sí, la pluralidad y la alteridad son ilusorias. Frente a ello, y profundizando sobre una filosofía que reflexione a partir de la experiencia religiosa, Marcel indica que la individualidad solo puede existir suspendiéndose a un acto de creación que supone una libertad distinta a ella: "la negación absoluta del solipsismo es la condición previa de toda vida espiritual" ( $J M$, p. 62). De este modo, Dios aparecería como aquello en que los pensamientos se comunican, como "el fundamento real de la comunicación entre individualidades" ( $J M$, p. 62). El problema aquí es que la ambigüedad de la comunicación entre las individualidades se debe a que hay, por un lado, una comunicación espiritual que es amor, y, por otro, una comunicación mecánica, externa (que no es más que su parodia), y que tiene lugar en tanto que el individuo se constituye partiendo de la existencia empírica. Mientras que si las individualidades se comunican de esta manera

es más bien un conjunto de sendas o rutas que pretenden profundizar en el misterio del ser, sin llegar a conceptualizarlo ni encerrarlo en un sistema. A esta forma de concebir la búsqueda filosófica la denominó Marcel «filosofía concreta» y «filosofía existencial». (...) La característica peculiar que adopta esta búsqueda en el pensamiento de Marcel es el establecimiento de dicotomías: existencia-objetividad, existencia-ser, problema-misterio y reflexión primera-reflexión segunda. El ojetivo de tales distinciones es establecer un ámbito de la realidad dotado de una plenitud y un peso ontológico, que impide su reducción a algo manipulable y modificable; y en estrecha conexión con dicha afirmación del ser, realismo, encontrar un acceso cognoscitivo a la realidad, sin objetivarla ni cosificarla, filosofía concreta. Que el acceso tiene que ser cognoscitivo, pero no conceptual-judicativo, es muy claro para Marcel -éste es el punto en el que se aleja de Kant y del realismo, como él lo interpreta-; ahora bien, la manera de determinar el sentido de esa vía cognoscitiva que él llama «reflexión segunda» está lastrada de cierta ambigüedad en aspectos esenciales, por lo que no es extraño encontrar textos de Marcel en los que se vislumbra una postura agnóstica, irracionalista y, en alguna de sus primeras obras fideísta. La lucha por salir de los límites de su planteamiento es el rasgo más característico del modo de pensar de Marcel, esa seña de identidad que hace de su filosofía un pensamiento personal y diferenciado del resto. Para referirse a esa situación fronteriza de su pensamiento Marcel eligió el término de «filosofía del umbral». (...) El pensamiento de Marcel se dirige del idealismo al realismo y culmina en una filosofía concreta, que siempre mantuvo su carácter de senda entre Escila y Caribdis, entre decirlo todo acerca de la realidad o guardar silencio". 
mecánica, se destruyen en cuanto tales, puesto que en rigor no hay verdadera exterioridad por no haber verdadera interioridad, y para darse es preciso ante todo pertenecerse. Esto quiere decir que para ponerse en relación con otros es necesario que la individualidad interiorice su contenido empírico, de modo que se halle como una individualidad en todo acto de amor, y se defina esencialmente en el amor.

El amor, dice Marcel, crea su objeto, no en el sentido subjetivista o idealista, puesto que la realidad del ser amado es esencial en el amor, por lo cual no habría una verdad subjetiva del amor que sea trascendente a la realidad del amado. En este sentido, el amor sería el único conocimiento real y adecuado, puesto que "solo para el amor la individualidad del amado no se dispersa, no se desmenuza en quién sabe qué polvo de elementos abstractos" (JM, p. 63). Esta realidad del amado se mantiene, justamente, en tanto que el amor lo pone como trascendente a toda explicación o reducción. Así, el amor se dirige a lo eterno en tanto que inmoviliza al ser amado por encima del mundo de las génesis y las vicisitudes, razón por la cual el amor es la negación del conocimiento que ignora toda trascendencia, es decir, el conocimiento objetivo. El amor, pues, debe aparecerse a sí mismo como un conocimiento perfecto en tanto que en él no puede disociarse el ser del aparecer del ser amado ${ }^{32}$. Claro que, como el amor tiene su contrapunto en una reflexión que supone la distinción entre sujeto y objeto, entre apariencia y realidad, debe definirse, dado su formalismo, como lo que se encuentra "más allá de todo conocimiento (au-delà de toute connaissance)". Sin embargo, la necesidad de un principio de justificación del amor aparece como necesario en el orden de lo finito, puesto que podríamos sumirnos en una ilusión de lo supuestamente amado. La paradoja de que el amor sea, a la vez, lo injustificable y lo que debe justificarse se mantiene mientras que la reflexión no se suprima totalmente, es decir, en tanto nos encontremos en el orden de la finitud. Si bien esto es posible en Dios porque para Él no puede haber esta disociación entre apariencia y realidad, en el amor entre los hombres, en el orden de lo finito, el amor sigue siendo verdadero en cuanto no se detiene en el conocimiento, sino que afirma el valor de su objeto más

\footnotetext{
32 Recordemos que nos encontramos en el contexto de la primera parte del Journal Métaphysique, en el que Marcel intenta desbaratar el idealismo de Bradley, quien propugnaba una disociación entre la apariencia y la realidad, para alcanzar el Espíritu que sintetiza ambos en un saber absoluto.
} 
allá del orden relativo y contingente del mérito o desmérito; "es que ese amor recibió en sí la mediación de lo divino" (JM, p. 64). Esta paradoja del amor se debe a que lo verdadero se afirma solo en el orden de la reflexión, y el amor es justamente lo que la trasciende, por lo cual la idea de conocimiento aplicado al amor parece engañosa. El amor no se dirige a lo amado en sí, entendiendo esta expresión como si se tratase de la esencia del amado. Al contrario, "el amor afecta a lo que está más allá de la esencia (l'amour porte sur ce qui est au delà de l'essence)" (JM, p. 64) ${ }^{33}$. El amor es, para Marcel, "el acto mediante el cual un pensamiento se hace libre pensando una libertad". Así, este va más allá de todo juicio referido a la esencia, mientras que el amor es la negación misma de la esencia en tanto que implica la fe en la renovación perpetua del ser mismo, es decir, la creencia en que nada es ni puede ser nunca absolutamente perdido. En tanto que el ser que ama hace del ser amado un objeto sobre el cual realiza juicios, lo pierde como amado, lo pierde como sujeto libre, sosteniéndose sobre las acciones que dicho ser realiza, pero perdiéndolo como ser original e irreductible que él es. Cuando uno ama, se prohíbe absolutamente juzgar al amado, colocando al ser amado más allá del orden de los méritos o desméritos, por lo cual Marcel afirma que "el tú no juzgarás de la moral cristiana debe considerarse como una de las fórmulas metafísicas más importantes que existen” $(J M, \text { p. 65 })^{34}$.

\footnotetext{
${ }^{33}$ Podemos notar aquí una expresión que podríamos rastrear a la reflexión platónica, así como luego aparecerá también en Emmanuel Lévinas, que indica la supremacía del Bien sobre el Ser.

${ }^{34}$ En otro texto, Marcel escribe: "Il faut donc renoncer à croire que lorsque nous aimons nous voyons les choses ou les êtres tels qu'il sont en soi, en ce sens que l'amour serait l'approximation la plus parfaite de la vérité de ceux-ci, et comme l'imitation d'une connaissance adéquate. L'amourne peut se fonder que comme acte; lejustifier objectivement, c'est le nier purement et simplement. A la rigueur par suite aucun être n'est digne d'être aimé, si par dignité on entend quelque chose qui objectivement devrait entraîner l'amourun mérite. L'amour est toujours nécessairement une grâce - l'ordre de l'amour est par delà le monde relatif du mérite et du démérite (qui se suspendent à des finalités collectives), c'est l'ordre du gratuit; et ce ne pas une monde; tandis que la sphère des rapports étiques en s'affirmant tend nécessairement à se totaliser en système, l'ordre de la grâce se nierait en devenant un monde [en nota al pie: Là est toute la différence entre la morale démocratique qui n'est qu'une et la morale chrétien ne qui est plus qu'une morale], et l'arbitrair en 'est que l'envers du métaphysique (considéré dans son rapport avec l'éthique c'est-à-dire avec l'abstrait). Si donc on peut dire que tout amour est en Dieu, ce n'est pas en ce sens que tout amour enveloppe confusément une connaissance parfaitement adéquate, mais en ce sens que tout amour est l'élan d'une liberté qui n'est qu'en prenant son point d'appui hors d'elle, c'est-à-dire en créant" (FP, pp. 99-100).
} 
Ya dije que el amor que se prohíbe toda reflexión es el que ha experimentado la mediación de lo divino. Es decir que pensando al ser amado como partícipe en Dios es como se coloca efectivamente en este orden trascendente con respecto a todo juicio, es como se concibe como valor absoluto. O mejor dicho (para excluir toda interpretación psicologista), la justificación del acto mediante el cual se afirma esta trascendencia de la criatura consiste postular su filiación divina (filiation divine). (JM, p. 66)

Este texto debe comprenderse desde las coordenadas de lo que significa la fe para Marcel. En efecto, es la fe la que hace posible hacernos libres al pensar la libertad divina y al afirmar, al mismo tiempo, otras libertades que se suspenden también de ella, por lo cual la fe funda la comunicación de los espíritus, la intersubjetividad. Participamos de Dios en tanto que tenemos fe en él, y no existe una verdad de esta participación que sea trascendente a la fe misma ${ }^{35}$. Pero la participación de los otros espíritus en Dios no es algo accidental o contingente a la fe, sino que se encuentra implicada absolutamente en el acto de fe, aún cuando la fe de los demás no pueda existir para nosotros. De allí que nos veamos en la necesidad de disociar de algún modo la participación de la fe, lo cual acarrea graves dificultades. En rigor, en el marco de la fe, la participación va a manifestarse como hecho.

Debemos subrayar la dificultad que presentan estos textos del Journal recordando que Marcel aún se mantiene en un lenguaje idealista, apresado también por las dificultades propias del idealismo. Sin embargo, podemos detectar la fuerza argumentativa de la intuición marceliana de la irreductibilidad del ser personal al conocimiento. El amor, como fenómeno que expresa eminentemente la comunicación interpersonal, debe escapar de las categorías lógicas y objetivistas para poder comprenderse a sí mismo. De lo contrario, no solo perderemos al amor como tal, sino también a las personas en comunión. Pero esta imposibilidad de la reducción del amor al conocimiento se sostiene en la participación, que desde el marco de la fe se

\footnotetext{
35 "La participation n'est pas un fait, elle n'est pas une donnée de l'esprit; elle est une exigence de la pensée libre, exigence qui se réalise en se posant puisque sa réalisation ne dépend d'aucune condition extérieure à elle. On peut cependant distinguer deux moments de la participation, suivant que celle-ci est définie comme un objet de la pensée ou que celle-ci renonçant à sa fonction de sujet pensant s'abandonne entièrement à la participation; ce second moment seul mérite d'être appelé la foi. La foi en un certain sens est plus qu'un acte immanent puisqu'elle est l'achèvement d'une dialectique tout orientée vers la transcendance" (FP, p. 93). Este texto vuelve a citarlo Marcel en DH, p. 45.
} 
entiende como comunión con Dios y con aquellos que dependen también de Él. De este modo, nos encontrarnos aquí con la noción de fraternidad cuyo necesario contrapunto es el de paternidad divina. Solo en este marco se puede afirmar el valor absoluto de la persona humana, y su esencial originalidad e irreductibilidad. En este sentido Marcel no concuerda con Kant en lo que respecta al fundamento de la moral; no se trata, en efecto, de un respeto a un otro cualquiera, sino de una comunión efectiva con el otro; no se trata de la defensa de individuos, sino del reconocimiento de las personas en su alteridad, como $\operatorname{seres}^{36}$. Lo que resulta claro, y se mantiene en la obra de Marcel, es entender al sujeto y al otro como seres espirituales que se encuentran, y que solo en dicho encuentro llegan a ser libres, sostenidos a su vez por Dios, quien es el fundamento mismo de la participación. Libertad,

\footnotetext{
${ }^{36}$ En el contexto de pensar lo espiritual, afirma Marcel que solo puede llamarse espiritual una relación de ser a ser: "Mais de ce même point de vue, l'idée kantienne de fin en soi n'apparaît-elle pas bien étriquée, bien juridique? Ce qui compte, c'est le commerce spirituel entre des êtres, et il s'agit ici non de respect, mais d'amour" (JM, p. 207). Y más adelante prosigue con la crítica: "Je sais bien qu'un être m'a toujours paru respectable en raison même de l'amour qu'il a inspiré (ou dont il a étéin justement privé). Au fond, le rationalisme kantienm'est de plus en plus étranger. Ce n'est pas en tant qu'incarnation de la raison qu'un être m'intéresse; comme tel, il n'est tout de même qu'un «lui». Kant a sans doute considérablement exagéré la valeur de l'autonomie comme source de valeurs. Je sais bien qu'il s'est avant toute préoccupé de rechercher ce qui peut être universalisé, et qu'une morale sentimentale lui est apparue comme intenable par cela même qu'elle repose sur un donné contingent, sur quelque chose qui peut ne pas être (ou qui n'est pas exigible en droit). En reprenant la langage dont je me suis servi précédemment, je dirais volontiers qu'ils'est pacéau point de vue technique. A quelles conditions quelqu'un (n'importequi) peut-il agir ou vouloir moralement? La réponse doit être universelle, c'est-à-dire valable même dans le cas $X$ le moins favorable. La grande question est de savoir si en procédant ainsi on ne se met pas en dehors des conditions de la vie spirituelle proprement dite" (JM, p. 207). Julia Urabayen Pérez explica (2001, p. 230): "La libertad es mucho más que autonomía. El orden de la libertad es el de la disponibilidad y el amor. Para Marcel la ética kantiana, por ser una ética de la autonomía, desconoce que la libertad no se reduce a autonomía, sino que está en el orden del ser". Y más adelante agrega: "La ética que propuso Marcel no es una ética formalista y universalista, sino una ética concreta, que tiene en cuenta a las personas y a su situación. Es una ética del amor, de la disponibilidad y de la fidelidad. Es la afirmación del otro en tanto que ser y en tanto que acceso al ser" (Urabayen, 2001, p. 232). Claro que la opción marceliana por una moral del amor presenta muchas dificultades, pero no deja de ser interesante la remisión a una metafísica de la comunión y la alteridad para la fundación de una ética. Quizá Paul Ricœur (2006, pp. 173-327) haya llevado a cabo una suerte de síntesis entre ambas corrientes, una más formalista y otra más existencial.
} 
amor y fe son, pues, inseparables en la filosofía marceliana ${ }^{37}$. Y el amor no es sino el nombre para esta participación entre los seres del mundo y el ser divino, participación que exige quebrar con el paradigma sujeto-objeto si se quiere reflexionar sobre ella debidamente. En la segunda parte del Journal, Marcel escribe:

Amar no es conocer adecuadamente; es posible que el amor dispense un conocimiento privilegiado, pero lo precede como precede también a la evaluación. Apercibo todavía otro punto: que el amor está bien vinculado a aquella salida del yo a que antes hice alusión; en este sentido, implica la liberación del yo que, lejos de ponerse como esencia, surge como amante (jaillit comme amant). El amor surge como invocación, como llamamiento del yo al yo. Y aquí se aplica perfectamente lo que dije antaño de la oposición entre invocación y señalamiento. Sin embargo, hay que andar con cuidado. Del hecho de que la invocación no se dirija a lo que yo denominé el yo-fuente de informaciones (moi-source de renseignements), ¿puede inferirse que se dirija a un yo desprovisto de predicados? Yo no lo amo a causa de lo que es, amo lo que él es, porque es él, y, por consiguiente, me anticipo audazmente a todo lo que pueda entregarme la experiencia, a todos los predicados en que ésta se deposite. Se me contestará, en verdad, que en los orígenes de esta anticipación debe haber ya el reconocimiento de un predicado, pero yo pienso que eso es falso; hay un acto, un estado, una manera de ser, como se quiera, que puede asimilarse por la conciencia descriptiva al reconocimiento de un predicado, pero en realidad es un inesperado enriquecimiento de mi ser (un enrichissement inattendu de mon être). (JM, pp. 216-217)

Nuevamente nos encontramos con la necesidad de que el yo se libere de sí mismo para alcanzar su libertad y su ser. Este yo deja de considerarse a sí mismo de un modo hipostático y esencial, como una sustancia o cosa, para surgir, en última instancia, como amante, es decir, para acaecer como intencionalidad a su otro con quien comulga. Es el amor lo que invoca al yo y, por tanto, también al otro yo, al tú. Yo y tú se constituyen en el seno de la comunión amorosa del encuentro, por lo cual el amor surge como invocación, como llamado al $\operatorname{ser}^{38}$. La invocación -con su carácter mágico- $(J M, \mathrm{pp}$.

\footnotetext{
${ }^{37}$ En una de sus últimas obras escribe Marcel: "Mais ce que doit être réservé absolument, et nous aurons à voir de plus en plus clairement pourquoi, c'est le domaine où la liberté $s$ 'exerce souverainement, et ce domaine est aussi celui d l'amour et, ajouterai-je, de la foi", (DH, p. 102).

38 "Yo soy ser en la medida en que invoco a un tú, para el cual yo también dejo de ser un él, para hacerme un tú. Ser es este enriquecimiento, esta plenitud sobrevenida. Si la sensación
} 
292-294) se opone al señalamiento, así como el yo del amor se opone a una sustancia a la que corresponden diversos predicados. No se trata, en efecto, en el orden del amor de un yo que sea, como Marcel llama, una fuente de informaciones o de cualidades, sino que se trata de un ser que trasciende toda predicación o cualificación. De allí que el amor sea gratuito y una apuesta audaz a lo que el otro me revelará en el encuentro. Así, se comprende el amor desde el misterio ${ }^{39}$.

Marcel intenta una suerte de definición del amor. Siguiendo estos lineamientos, "no hay amor sino allí donde hay renovación absoluta (renouvellement absolu), y aun renacimiento. El amor es la vida que se descentra (l'amour c'est la vie qui se décentre), que cambia de centro" (JM, p. 217). Que el amor sea la vida que se des-centra significa, justamente, que el lugar que la modernidad le ha otorgado al sujeto, esto es, el centro mismo de toda actividad, pensamiento y vida, se encuentra absolutamente des-quiciado. Como una suerte de revolución copernicana, el sujeto deja de ser el eje axial de la experiencia y de la vida para depender totalmente de una alteridad con la que entra en comunión ${ }^{40}$. No soy yo primeramente, para luego comunicarme con un otro, sino que soy yo gracias a ese otro a quien

era participación en lo sentido, y la existencia tipo era encarnación o participación en mi cuerpo, el ser podríamos definirlo por ahora como participación en el amor" (Vasallo, 1938, p. 39). "The encounter is executed and accomplished by the Thou; it is the result of love. At the same time, for me to participate in being is to participate in the personal life and fate of a fellow human who trusts me -in an I-Thou relation-and who has thereby been entrusted to me; from this person I receive a reality -within the encounter-that can be neither answered on questionnaires nor tabulated in statistics, because it cannot be formulated or objectifies. It occurs only in the consummated existential being-together-only in the reality of love. Such an act of communication between humans grants a sharing of the common reality of the totality -the reality of being. (...) Being becomes real as a being-together-withsomeone-else" (Gabriel, 1984, p. 301).

39 "Sans doute il serait absurde de dire que l'amour porte sur de l'inconnaissable; ce qui est mystérieux, ce n'est pas l'objet de l'amour comme tel, mais plutôt le type de rapport que l'amour enveloppe. C'est en vain que l'amant dénombre les caractères, les mérites de l'être aimé; il est certain a priori que cet inventaire ne lui rendra pas son amour transparent pour lui-même" (JM, p. 226).

${ }^{40}$ Es interesante, en este sentido, lo que entiende Marcel por un humanismo auténtico: "Qu'entendre par ces mots [humanisme authentique], sinon un humanisme de la personne, ou plus profondément encore du TOI, c'est-à-dire de l'ipséité, tel que je crois découvrir chez Érasme" (Marcel, 2004, p. 33). Este humanismo del tú puede considerarse muy cercano al que propone Emmanuel Lévinas (2006), donde el acento está puesto no en el yo sino en el otro. 
$\mathrm{amo}^{41}$. La fuente de los valores, por ello, no puede ser meramente un yo que se considera autónomo, como en el caso de la moral kantiana, sino que debe buscarse en la participación misma, en el encuentro entre dos seres, que los constituye y les otorga su valor absoluto. Sin comunión no hay valor, razón por la cual la desesperación, es decir, la impugnación de todo valor por la conquista última de la nada, se sostiene en la soledad ${ }^{42}$. Lo inmoral, en efecto, se encuentra en la voluntad de no-participación, en el hecho de desligarse de una vida en común que me fundamenta y que me hace libre ${ }^{43}$. $\mathrm{El}$ amor, pues, trasciende toda lógica de exclusión y división, trasciende toda categoría de lo mismo y lo otro, y permite pensar al sujeto desde "un otro lugar", desde el nosotros en el que adquiere consistencia ontológica, puesto que le otorga su valor de ser (a diferencia del deseo, que siempre tiende a un objeto determinado y que, por ello, podría colocarse en las coordenadas del tener $)^{44}$.

El amor, análogamente a como se comprenden las virtudes teologales en el cristianismo, adquiere en Marcel un lugar cardinal: tanto la fe como la esperanza no son nada sin la caridad o el amor ${ }^{45}$. Y ello porque amar significa

\footnotetext{
${ }^{41}$ En el marco de pensar la muerte del ser amado, Marcel habla de lo indefectible, de aquello que no puede fallar, que es justamente la presencia del ser amado. Hay lo indefectible porque sin él no podría haber sujeto alguno: "L'être que j'aime est toujours là. Il est là comme moi-même et au même titre; je ne suis qu'en liaison maintenue avec lui; et si cette liaison se rompait, je ne serais plus" (PI, p. 205).

42 “C'est qu'au fond le désespoir se confond avec la solitude, et il n'y a pas de valeur sans communion. Seulement, ces mots peuvent tromper: il y a une solitude, celle des grands contemplatifs, qui est une communion; et il y a aussi de fausses communions qui ne sont qu'alienation" (PI, p. 166).

43 “Tout ce qu'on peut dire, je crois, c'est qu'entant que j'agis d'une façon immorale, je m'exclus moi-même d'une certaine vie, je refus d'y participer; et je me rends par là même pour l'avenir cette participation plus difficile, parce que mon acte contribue à me déterminer moi-même" (JM, p. 211). Marcel habla en este caso de "monadismo moral puro" (JM, p. 211).

44 "L'opposition entre le désir et l'amour constitue une illustration très importante de l'opposition entre l'avoir et l'être. Désirer, en effet, c'est avoir en n'ayant pas. Le désir peut être regardé à la fois comme autocentrique et comme hétérocentrique (polarité du même et de l'autre). L'amour transcende l'opposition du même et de l'autre pour autant qu'il nous établit dans l'être" (EA, p. 220).

${ }^{45}$ En el contexto de pensar la muerte del otro, que es en última instancia la piedra angular de la metafísica del nosotros, dado que la muerte parece ser la objeción más terrible a
} 
entrar en comunión, o mejor dicho, acoger la comunión en la que ya me encuentro. La participación, en todos sus niveles, se realiza amorosamente, se confunde con el amor mismo ${ }^{46}$. La oposición entre libertad y alteridad, entre donación y autonomía, entre generosidad y manipulación, pierde fuerza desde el momento en que la participación es afirmada, desde el momento en que decidimos pensar en torno a la necesaria tensión entre los polos. Pero a la vez esta participación, que es amor, no puede comprenderse sino universalmente, como alcanzando a todos los seres siempre. De allí que el amor deba reflexionarse desde las experiencias religiosas de la santidad ${ }^{47}$ y de la presencia de un inmemorial que se manifiesta como llamado a la plenitud: heterogénea respecto al objeto del deseo, nunca asequible en la experiencia itinerante del ser humano $\mathrm{y}$, sin embargo, siempre presente en su andar ${ }^{48}$. La filosofía, entonces, no puede desligarse sin más de los símbolos

la realidad de la participación y de la presencia, Marcel afirma: “... [L]a valeur d'une telle intimité, en particulier en ce qui regarde le commerce entre les vivants et les morts, sera d'autant plus haute et plus irrécusable que cette relation se situera plus nettement dans un monde de disponibilité spirituelle totale, c'est-à-dire, de pure charité, et je note en passant qu'un dialectique ascendante de la fidélité créatrice correspond à la dialectique de l'espérance à laquelle j'ai fait allusion tout à l'heure" (PA, p. 82).

${ }^{46}$ Con la rigurosidad y la claridad que lo caracteriza, Paul Ricœur (1992, pp. 62-63) escribe:

"Je voudrais maintenant confirmer cette caractérisation du style philosophique de Gabriel Marcel, en revenant à la polarité évoquée au début de cette étude entre philosophie de l'existence et philosophie de l'être. En un sens, les trois thèmes que je viens d'invoquerincarnation, liberté-don, invocation - ressortissent à une philosophie de l'existence. Mais ces trois thèmes, pris individuellement ou en bloc, sont enchevêtrés à un mouvement de trascendance qui fait passer d'une philosophie de l'existence à une philosophie de l'être. La notion de participation, trois fois mentionée, remplit précisément cet office. Mais cette implication de la philosophie de l'être dans la philosophie de l'existence est sourtout visible sur le plan de la liberté-don. C'est seulement par abstraction, en effet, qu'on peut distinguer cette qualité de liberté de ce qui est appelé sommairement mystère ontologique; la libertédon est foncièrement un consentement à l'être. Mais cette implication de la philosophie de l'être dans la philosophie de l'existence, dans le moment de l'attestation du toi, n'est pas appelée en vain invocation, tant la question de la prière adressée au Toi absolu est entrelacée à celle de la reconnaissance d'autrui, en tant que le Toi transcende le Lui".

47 “Je dirai qu'une philosophie de l'amour ne semble bien pouvoir se développer que dans un paysage qui comporte, à l'horizon, les grandes figures inaccesibles de la sainteté; mais ces figures-limites, il serait contraire à tout raison et à toute humilité, de vouloir comme les transporter au milieu du paysage, c'est-à-dire de l'expérience et de la réflexion qui s'y articulent" (Marcel, 1954, p. 379).

48 "Ne faudrait-il pas dire plutôt que tout en lui nous renvoie-mais dans une confusion que la raison est impuissante à mettre en ordre -à un immémorial tragiquement effondré, mais 
y de los testimonios de la religión, y debe repensar sus categorías a partir del contrapunto misterioso que nos ofrecen los datos de una Revelación trascendente. Vemos que, en Marcel, hay un vaivén constante entre los discursos metafísicos y religiosos, y en una época donde la fenomenología ha virado de algún modo también hacia lo teológico, se hace necesario revisar los modos en que un campo y el otro acuden a la reflexión en torno a lo humano.

\section{Referencias}

Cañas Fernández, J.L. (2005). Influencia del primer Gabriel Marcel en el primer Jean-Paul Sartre. Anuario Filosófico, 38(2), pp. 381-403.

Gabriel, L. (1984). Marcel's Philosophy of the Second Person. AA.VV. The Philosophy of Gabriel Marcel (pp. 295-311). Carbondale: Southern Illinois University.

GlenN, J. (1984). Marcel and Sartre: The Philosophy of Communication and the Philosophy of Alienation (525-552) AA.VV. The Philosophy of Gabriel Marcel. Carbondale: Southern Illinois University.

Grassi, M. (2013). O Deus da fé na filosofia concreta de Gabriel Marcel. C.A.F. Silva (Org.). Encarnaçâo e transcendência. Gabriel Marcel, 40 anos depois (pp. 21-44). Cascavel: Edunioeste.

Grassi, M. (2011a). Existencia y encarnación en Gabriel Marcel. Contrastes. Revista Internacional de Filosofia, XVI, pp. 211-228.

Grassi, M. (2011b). La reflexión segunda y el acceso al misterio del Ser en la filosofía concreta de Gabriel Marcel. Nuevo Pensamiento: Revista de Filosofía, 1(1), pp. 21-46. Versión online: http://facultades-smiguel.org.ar/maximo/

Grassi, M. (2009). El hombre como ser encarnado y la filosofía concreta de Gabriel Marcel. Revista de Humanidades, 19-20, pp. 9-28.

Henaff, M. (2012). Le Don des philosophes. Repenser la réciprocité. Paris: Seuil.

non point aboli? Et que nous avons, chacun dans l'humble mesure des forces ou des grâces qui lui sont imparties, à opérer, d'ailleurs, dans une liaison tendre et souffrante les uns avec les autres, le redressement toujours imparfait des images déformées et énigmatiques que nous propose d'abord le Désir?" (Marcel, 1954, p. 379). 
LévinAs, E. (2006). Humanismo del otro hombre. México: Siglo XXI Editores.

Marcel, G. (2007). Don et liberté. Bulletin de l'association Présence de Gabriel Marcel, 17, pp. 25-43.

Marcel, G. (2004). Erasme et l'humanisme du Toi. Bulletin de l'association Présence de Gabriel Marcel, pp. 25-34.

Marcel, G. (1984). Reply to John D. Glenn, Jr. AA.VV. The Philosophy of Gabriel Marcel (pp. 551-552). Carbondale: Southern Illinois University.

Marcel, G. (1967 [1940]). Essai de philosophie concrète (RI). Paris: Gallimard.

Marcel, G. (1964). La dignité humaine (DH). Paris: Aubier-Montaigne.

Marcel, G. (1961). Fragments Philosophiques (1909-1914) (FP). Louvain-Paris: Nauwlaerts-Vrin.

Marcel, G. (1959). Présence et immortalité (Journal Métaphysique 1938-1943, et autres textes) (PI). Paris: Flammarion.

Marcel, G. (1951). Le Mystère de l'être (I: Réflexion et mystère) (MEI). Paris: Aubier-Montaigne.

Marcel, G. (1951). Le Mystère de l'être (II: Foi et réalité) (MEII). Paris: AubierMontaigne.

MarCel, G. (1954). Notes pour une philosophie de l'amour. Revue de Métaphysique et de Morale, 4, pp. 374-379.

MARCel, G. (1949 [1933]). Position et approches concrétes du mystére ontologique $(P A)$. Louvain-Paris: Nauwlaerts-Vrin.

MARCel, G. (1946). L'existence et la liberté humaine chez J.-P. Sartre. AAVV. Les Grands appels de l'homme contemporain (pp. 111-170). Paris: Éditions du temps présent.

MARCEL, G. (1944). Homo viator: prolégoménes a une métaphysique de l'espérance $(H V)$. Paris: Aubier-Montaigne.

Marcel, G. (1935). Journal Métaphysique (JM). Paris: Gallimard.

Marcel, G. (1935). Etre et Avoir (EA). Paris: Aubier-Montaigne.

Riceur, p. (2006). Sí mismo como otro. Madrid: Siglo XXI.

Riceur, P. (1992). Réflexion primaire et réflexion seconde chez Gabriel Marcel.

Lectures 2: La Contrée des philosophes (pp. 49-67). Paris: Éditions du Seuil. 
SARTRE, J.-P. (1998). El Ser y la Nada. Buenos Aires: Losada.

Urabayen Pérez, J. (2004). La filosofía de Marcel: del idealismo al realismo, del realismo a la filosofía concreta. Pensamiento: Revista de Investigación e información filosófica, 60(226), pp. 115-136.

Urabayen Pérez, J. (2001). El pensamiento de Gabriel Marcel: un canto al ser humano. Pamplona: EUNSA.

Vasallo, A. (1938). Cuatro lecciones sobre metafisica: Itinerario de la realidad en el "Diario Metafísico" de Gabriel Marcel. Buenos Aires: Colegio libre de estudios superiores. 